\title{
VIOLÊNCIA E INDISCIPLINA NO ESPAÇO ESCOLAR NA COMUNIDADE RIBEIRINHA DE RIO JUBA, NO MUNICÍPIO DE CAMETÁ-PA, NO ANO DE 2019.
}

\author{
MARIA CLAUDETE GARCIA PINTO
}

\section{RESUMO}

Esta pesquisa buscou descrever a violência e como esta é trabalhada na prática docente diante dos desafios ao combate da indisciplina no espaço escolar na comunidade ribeirinha de Rio Juba, no município de Cametá, no período e 2019. A metodologia utilizada foi o estudo Misto com desenho DITRAS, tendo o enfoque Misto direcionado pelo alcance exploratório descritivo. A pesquisa teve como variáveis invetigadas a violência, a prática pedagógica, e a indisciplina tendo como campo investigativo a area da educação mais especificamente a comunidade ribeirinha de rio Juba localizada no município de Cametá. Os resultados obtidos neste trabalho, identifica-se que os conceitos de violência compreende-se como um fenômeno essencialmente humano, construído histórica e culturalmente pelas civilizações, que ao longo da história ocorre por influência de fatores psicológicos, sociais e culturais; conclui-se que a violência escolar é reflexo da sociedade justificando que as causas que contribuem o aumento da violência escolar são problemas que o aluno traz de casa; a escola está sendo o local que ocorre às violências geradas por problemas familiares, por desestruturação familiar.

Palavras-chave:Violência. Prática docente. Indisciplina.

\begin{abstract}
This research sought to describe violence and how it is worked in teaching practice in the face of challenges to combat indiscipline in the school space in the riverside community of Rio Juba, in the municipality of Cametá, in the period and 2019. The methodology used was the Mixed study with DITRAS design, with the Mixed approach directed by descriptive exploratory reach. The research had as variables invetigated violence, pedagogical practice, and indiscipline having as investigative field the area of education more specifically the riverside community of Juba River located in the municipality of Cametá. The results obtained in this work identify that the concepts of violence are understood as an essentially human phenomenon, historically and culturally constructed by civilizations, which throughout history occurs due to the influence of psychological, social and cultural factors; it is concluded that school violence is a reflection of society, justifying that the causes that contribute to the increase in school violence are problems that the student brings from home; the school is being the place that occurs to violence generated by family problems, family disstructure.
\end{abstract}

Keywords:Violence. Teaching practice. Indiscipline. 


\section{INTRODUÇÃO}

Nesta pesquisa de mestrado, tem-se como objeto central a violência âmbito escolar. Aborda-se a prática docente e quais os desafios que os docentes enfrentam para combater a violência e a indisciplina no espaço escolar na comunidade ribeirinha de rio Juba, no município de Cametá, no período e 2019. Investigou-se os efeitos da violência e seus danos no âmbito escolar buscando compreender quais os reflexos da violência no processo de desenvolvimento educativo do aluno.

A violência designa fatos sobre as ações humanas que perturbam a paz ou a ordem social, em que cabe a escola ainda nas series iniciais trabalhar a paz, os valores ou a ordem social, a formação do sujeito cidadão na implementação de política educativa que direcione a prática pedagógica sobre a paz e a cidadania para que essas ações promovam o ambiente educacional harmonioso e a comunidade em geral seja impactada com a formação de pessoas do bem.

É preciso que os docentes realizem oficinas abordando alguns tipos de violência como social, sistêmica, econômica, psicológica, ambiental, corporal, física, sexual, de gênero, racial e intrafamiliar. Observa-se que os fatos problemáticos ocorridos estão em evidencia e contidos em todos os lugares, principalmente na escola pesquisada onde a violência no âmbito escolar apresenta-se de diferentes formas no cotidiano, podendo ser verbal, física ou psicológica. Na relação entre os alunos pode-se evidenciar de forma mais clara. A violência ainda pode ocorrer a partir dos educadores sendo que estes, não se percebe é que na realidade as escolas não estão preparadas para enfrentar a complexidade dos problemas atuais, ouvem relatos de casos de professor agredindo colegas de trabalho e alunos verbalmente na tentativa de conter a rebeldia desestabilizando o estabelecimento de ensino.

A violência é uma construção da realidade suportada pelos diversos lados do fenômeno social onde a educação escolar deve constituir-se em uma ajuda intencional, sistemática, planejada e continuada para os educandos durante um período continuo e extensivo de tempo, baseada em analise pesquisado pela experiência vivenciada na escola visitada, conclui-se que deve ser proposto maneira pelas quais ela se mostre efetiva e eficazmente os problemas a carretados pela violência na localidade ribeirinha, em que a escola deve mostrar ato social, onde a comunidade local vá além da sala de aula a sociedade em geral, enxergando o indivíduo em sua totalidade social, educacional ou seja em todos os momentos de seu dia-a-dia. 
A pesquisa discursa a temática Violência e a indisciplina no espaço escolar buscando fazer uma abordagem sobre a prática docente diante dos desafios ao combate da violencia e da indisciplina no espaço escolar na comunidade ribeirinha de rio Juba, no município de Cametá, no período e 2019. E nesse contexto a investigação ocorrerá no campo da educação tendo como contexto o município de Cametá a palavra "Cametá" vem do tupi "caa" (degrau, palanque, elevação) e Mutá (floresta, mato, vegetação densa) logo Cametá numa tradução livre significa "degrau da floresta". Segundo o IBGE de 2017 existem 134100 habitantes. A cidade de Cametá foi fundada em 24 de dezembro de 1635 e possui uma área de 3081, 367 $\mathrm{Km}^{2}$, possuindo vários patrimônios históricos na qual vou relatar apenas três como o Museu que fica na travessa benjamim constante, centro.

A justifica-se dessa investigação advém sobre o que acontece no meio social, surgindo então a ideia de desenvolver este trabalho tendo como tema abordado que chamou atenção e que vem se enfrentando na sociedade de maneira preocupante, fazendo com que sugerisse perguntas e objetivos descrever uma fundamentação discursão sobre a importância do tema, com as pessoas participativa da comunidade ribeirinha do Rio Juba em que os educadores e demais membros escolar devem ampliar ideias positivas e de paz, tendo muito esforço e empenho na identificação desses problemas com a qual se convive não só no ambiente escolar mais por muitos da comunidade ribeirinha de Rio Juba, para que assim se tenha um ambiente seguro e saudável no momento do ensino aprendizagem e na sociedade em geral.

A violência são ações que sempre acontecem no âmbito escolar geralmente reconhecido pelos discentes e até mesmo pelos docentes e funcionários em gerais, que limita sua compreensão para a ação que provoca danos visíveis e desordem um com os outros fazendo com que se torne um ambiente desagradável, mas com a busca da melhoria educacional surgiram novas práticas e durante a realização da oficina, foram utilizado fatos, tentaram abordar alguns tipos de violências na qual vem ocorrendo no âmbito escolar muitos são os diferentes tipos de violência que acontece na escola. Entretanto é importante que aconteça a implementação de programas de fundamentação de conhecimento de certos problemas em que se pretende intervir no contexto escolar, assim destaca-se a importância de que os educadores e em especial os órgãos de gestão das escolas disponham de instrumentos que permitam realizar um diagnóstico cuidadoso da situação, capazes de fornecer a verdadeira dimensão.

Pois cada dia está mais visível seja no ambiente escolar ou na comunidade, a violência é um problema preocupante, refere-se às condições importantes da sociedade que priorizam os interesses pessoais aos coletivos, analisando e refletindo sobre o entendimento de muitos 
docentes e discentes na instituição de ensino. Falando sobre os fatos problemáticos ocorridos que estão em evidencia e contidas em todos os lugares principalmente na comunidade ribeirinha de Rio Juba, deixando marcas profundo como o egoísmo, desajuste familiar e escolar, frequentemente a violência é atos de predominância na vida dos discentes e de mais seres humanos que acaba destruindo o amor entre os outros e trazendo esse problema preocupante que não deixa de existir nesta localidade entanto, a vivencia de elaboração e discursão, gera uma experiência essencial ao trabalho de pesquisa e sempre haverá o que aprender com e sobre o que refletir no tema aplicado na sociedade.

\section{A VIOLÊNCIA NO ESPAÇO ESCOLAR}

A violência na escola se manifesta de modo sutil, fazendo presente nos conteúdos que podem não ter significado para a vida dos discentes e principalmente quando a escola inviabiliza o pensar, a reflexão e a apropriação de conhecimento o diálogo na relação com os docentes que se caracteriza por práticas disciplinares e sem espaço em que visam à sujeição do educando, á submissão, a docilidade, o conformismo, quando o professor utiliza seu poder sobre o educando para impedi-las de pensar e expressar suas capacidades, tornando-se meros reprodutores de conhecimento em sua aprendizagem existe tipos de violência escolar que vem aumentando constantemente em nossa sociedade, sem dar-lhes condições concretas para a efetivação de tais necessidades, levantada sobre a violência sofrida por professores acontece em várias modalidades que não deixa de ser fatores sociais, culturais, políticos e econômicos de tal violência exigindo de nossos educadores novas posturas, novos comportamento, novas ações e formas de se expressar no contexto escolar, devidamente como por exemplo: o baixo salário recebido, o número absurdo de carga-horária, as turmas completamente lotadas, o tempo de serviço, as precárias condições físicas de algumas escolas e outras ações que formam um quadro que possibilita a violência deixando magoas profundas nas pessoas que fazem parte do grupo escolar.

A violência invade os espaços e acontece em todas as classes sociais econômicas são situações que ocorrem no interior das escolas principalmente com os alunos através dos apelidos de mal gosto, descriminação racial, isolamento social, ameaças, desrespeito, falta de carinho e atenção e com isso muitas das vezes as crianças acabam desistindo de seus objetivos por não terem estimulação e forem atingidos por esse problema desagradável.

$\mathrm{Na}$ atualidade a violência está tanto em relação ao que adentro os muros escolares quanto ao que se processa nos seu interior, a partir de sua dinâmica institucional, pois a violência que é muito pouco divulgado, muito pouco estudado e, então, muito pouco 
conhecido: a violência praticada pela escola e considerada como uma simples coisa na qual deveria ser reconhecida a partir de soluções para os problemas estruturais da educação que atinge níveis assustadores de docentes e discentes que não tem recebido incentivação nas informações que os levem a refletir sobre a própria realidade, superando seus sentimentos e invisibilidade social a que habitualmente convive em seu cotidiano escolar.

Telles (1996) é mais fácil se falar de violências no plural, ou seja, a violência urbana, a policial, a familiar e a escolar. Embora considerando que todas essas manifestações de violência estão imbricadas, vamos dar um maior destaque, neste texto, à violência escolar, sobretudo a que se manifesta de forma subjetiva nas relações sociais no interior da escola.

Candau enfatiza que (1995), é importante que "a escola seja um espaço onde se formam as crianças e os jovens para serem construtores ativos da sociedade na qual vivem e exercem sua cidadania” citam diferentes manifestações de violência que, de forma direta ou indireta, ocorrem no cotidiano das escolas brasileiras e, dentre elas, as que se colocam na categoria de violência na escola: depredação escolar, como a quebra de instalações, furto de materiais e pichações; brigas e agressões entre alunos, como roubos, insultos, brigas e exploração dos mais novos; agressões entre alunos adultos, como ameaças a professores e agressões verbais, físicas ou psicológicas impingidas pelos professores e outros profissionais da escola aos alunos.

O relato sobre esse processo de violência está em vários lugares ao mesmo tempo, é mais frequente na escola, esta é bastante vulnerável a esse tipo de ação, fruto de um tipo de mentalidade muito corrente de que algumas situações de acontecimentos na escola, que essa é considerada como o principal dentre todas as violências que se processa na sociedade.

A criança medrosa, ansiosa, depressiva, que se comportam de forma violenta ou estranha podem estar escondendo algo extremante grave. Esses são alguns dos muitos sinais, às vezes sutis, outros nem tanto, emitidos pelo ser humano, explicando-se que a violência de alunos e professores contra a escola e os próprios colegas só se resolve quando eles se sentem parte dela, "mas enquanto a gestão escolar não propuser a discussão de questões de convivência promovendo a participação dos docentes e discentes, eles continuarão se sentindo não pertencentes ao ambiente."

$\mathrm{Na}$ escola visitada não houve certo avanço na conscientização através da palestra e diálogo impostos com intuito de facilitar o problema encontrado na escola e mostrando a maneira adequada de uma boa sobrevivência, para que sejam desenvolvidas essas habilidades, também o professor precisa propor atividade que os façam raciocinarem mudanças entre todas. 
A violência na escola se manifesta de modo sutil e é a mais situada e divulgada pela mídia e não deixa de ser também facilmente identificada pelos profissionais da escola, pelos órgãos que a dirigem e pelas instituições policiais, continuava a existir a violência externa a escola e contra a escola, ela foi superada. A violência se expressa em várias modalidades pelos problemas internos.

\footnotetext{
Violência na escola é aquela que se produz dentro do espaço escolar, sem estar ligada à natureza e as atividades da instituição escolar: quando um bando entra na escola para acertar contas das disputas que são as do bairro, a escola é apenas o lugar de uma violência que teria podido acontecer em qualquer outro local. Violência da escola está ligada à natureza e às atividades da instituição escolar: quando os alunos provocam incêndios, batem nos professores ou os insultam, eles se entregam a violência que visam diretamente à instituição e aqueles que a representam. Essa violência contra a escola deve ser analisada com a violência da escola: uma violência institucional, simbólica, que os próprios jovens suportam através da maneira como a instituição e seus agentes os tratam (modos de composição das classes, de atribuição de notas, de orientação, palavras desdenhosas dos adultos, atos considerados pelos alunos como injustos ou racistas). (CHARLOT, 2002, p. 434)
}

Violência entre alunos: É a mais apontada pela maioria de professores tanto de escola pública, quanto de particular, na escola pública a violência está sendo um fato muito grande, que realmente os educadores estão tentando amenizar mas não é fácil existem determinados alunos que dentro da sala de aula apresenta horríveis comportamentos, e os professores tentam amenizar esse problema, mais a violência está existindo dentro da escola devidamente o uso de certas coisas que não é permitido no estabelecimento de ensino, nas escolas da rede particular de ensino, a violência acorre mais fora da sala de aula, especialmente na prática de esportes como por exemplo o bullying em que deixa os professores e pais mais preocupados com as consequências danosas para todos os que nele estão envolvidos, os problema social nas relações interpessoais mediadas pelo poder ressaltam as características de intencionalidade, crueldade, humilhação e submissão do outro.

Violência de aluno contra professor: A maioria dos fatos mencionados na escola é envolvidos por alunos de series mais elevada que praticam as ameaças moralmente, fisicamente e verbalmente na escola fora ou dentro da sala, diz que não quer participar da aula, faz bagunça xinga o professor, mesmo que não o atinja diretamente o educador se vê envolvido por ser solidário, ou pelo sentimento que experimenta está no lugar do colega agredido e até mesmo quando um aluno sai reprovado o professor recebe as critica horrorosa que deixa a sua personalidade arrasada. 
outros tantos fatores internos que podem estar relacionados à violência escolar levando o aluno ao fracasso escolar. (SILVA, 2009, p. 3).

Violência de aluno contra funcionário: São violências pouca mencionada pelos professores nas escolas porque ficam comedor de ser ameaçado, por isso evitam de tomar conhecimento junto com as pessoas da secretaria e da diretoria, os alunos que são violentos não obedecem os funcionários se eles fizerem alguma coisa como por exemplo expulsar no outro dia eles vem com tudo para cima muita das vezes tragam armamentos e acaba fazendo acontecer a violência até mesmo com sua própria família e com isso os funcionários encontrase uma série de dificuldade para fazer valer certas normas estabelecida na escola.

Violência de aluno contra a escola: É uma das violências que atinge a escola e é a modalidade mais conhecida como depredação, desrespeito e vandalismo ao patrimônio escolar na qual é praticada tanto por educandos quanto por outras pessoas ou grupos externos à escola, atingida por furto de materiais e equipamentos, quebra de instalações ou de equipamento, pichações e outros. A escola pública e a que mais mostra a precariedade por ser a mais frequente atingida pela violência, diferentemente da escola privada que dificilmente acontece esse tipo de ação. A violência contra a escola não acontece somente pelo vandalismo e sim também pela falta de cuidado e de manutenção, a depredação é qualificada como crime de fatos social, desvinculando-se de funções sociais e políticas.

Violência de professor contra aluno: Ocorre de várias maneiras e se refere a violência simbólica, mas além dela há outras formas de violência praticada pelo professor, a violência física, que se faz presente no cotidiano dos alunos em sala de aula, é pouco frequente, mas especialmente nas series iniciais.

Se destaca também a psicológica que é pouca estudada e os educadores não se percebem praticando-a até mesmo em uma resposta de forma tão agressiva, expulsar da sala, mandar para a direção e coordenação, fazer denuncia aos pais deixar sem recreio, retardar a saída comentário pejorativo (zombar) e castigar de maneira claramente humilhante, que deixa a criança desestimulada colocando-a para trás e até mesmo ameaçando o aluno a ser transferido para outra turma.

Em várias escolas a atenção dos professores é voltada para os comportamentos inadequados do que para os adequados, tornando-se um clima pouco prazeroso na sala de aula, ao invés de construir em construtivamente, coloca-se em lados opostos. Portanto é importante ressaltar que o uso de violência de professor contra aluno, seja física simbólica ou psicológica, constrói, na sala de aula, um ambiente pouco propício à aprendizagem, e na escola pública, constitui mais um fator de agravamento da exclusão social o que estão 
submetidas as parcelas de baixo nível socioeconômico da população, acontece o fracasso escolar, no qual esperamos que os professores adotem uma concepção de instituição como local de relações ou práticas sociais especificas, concluindo que essa violência nunca ocorra por parte deles em possuírem um elo de conhecimento.

Portanto, a escola tem papel importante na prevenção desse tipo de crime por ser o primeiro meio social do qual a criança participa, depois da família. A escola é um espaço de reprodução de estruturas sociais e de transferências de uma geração para outra que o legado econômico transforma.

2.1 A violência familiar e seus reflexos na formação discente.

O presente texto traz uma reflexão sobre a violência na formação do discente, entendendo que tal comportamento é apreendido por uma tradição, repassada de gerações para gerações, tal violência de gênero perpetua-se ao longo da história da própria educação, na maioria das vezes, dentro do seio familiar, independentemente do gênero, vítimas, o que reflete diretamente na forma com que somos tratados pelo Estado e pelas suas instituições.

Por tratar de um caso pouco explorado até o momento, a produção textual a explanação aqui apresentada são de extrema importância, não com a pretensão de mostrar a verdade, pois, de procurar um caminho a seguir na abordagem do tema, em que, apesar de muitos acreditarem que não haja mais violência preconceitos a combater, sabemos que a realidade não se apresenta dessa forma, todos os dias há acontecimentos mortes, ameaças enfim, tantas violência e comportamentos nos dias de hoje. Porém e muitos casos de violência sofrida.

Podemos dizer o que acontece na escola, constantemente os problemas são relacionados, reflexo do meio social dos convívios o comportamento de seu pais, as suas carências, conflitos e expectativas e especialmente do meio social básico e nuclear, a família. A violência se está presente no meio social, penetra as relações familiares e faz parte do cotidiano das famílias e consequentemente dos filhos.

Os filhos são reflexo de seus pais se mãe e o pai tem atitude destas, como é possível esperar que o filho respeite os professores se eles têm um comportamento de incitação à violência vai querer praticá-la dentro da escola. A família e sempre parte da solução da violência escolar, porque o pais devem seguir de perto a atividade dos filhos na escola. Neste contexto há outra dimensão da violência na escola que exige muito a atenção de todos, vigilâncias e intervenção dos pais no percurso escolar, vítimas de bullying os filhos, sendo que estudos fundamentados concluem que cerca de metade dos discentes são vítimas. Pois a 
família juntamente com escolas deve esclarecer a situação colabore-se ou promovam programas de atuação na escola, prevenção acompanhamento de toda a comunidade envolvida na escola.

Neste sentido, a violência na escola vem ganhando destaque na mídia e na sociedade nas últimas décadas está presente no cotidiano do ser humano, que se manifesta por meio de pensamentos ou de ações e resultam em sentimento de insegurança e a gente estabelece um pensamento linear que o problema é culpa da família, a escola tem esta tendência de culpar os pais, mas muitas vezes é desconsiderado estes e outras interferências que a família sobre uma sociedade violenta repercute também na família, fazendo com que os discentes ingresse nesse problema e desistam de aprender aquilo que diz a respeito de um futuro melhor, muitas vezes a importância da mesma reside sim em alterar a violência, onde acaba acontecendo na família.

A violência física a qual é considerada mais práticas para disciplinar os filhos, tornando-se seus sentimentos de raiva em frente ao agressor, ficando com dificuldade na escola de aprender a confiar nos outros, fica autoritário, comportamento e relacionamento inadequados e principalmente nas áreas emocionais efetiva e cognitivas, recendo formações diferenciadas do que deveria se adaptar.

$\mathrm{Na}$ família ainda persiste a visão de que as atitudes violentas dos homens seja algo natural e deixa de analisar a existência de cruéis comportamentos em relação aos que consideram fracos, por parte de sua masculinidade, constantemente essa prática se caracteriza no meio familiar por jogar algo sobre o outro, a justificativa mais apresentada é entre o casal, deixando a família desestrutura e prejudicando a vida estudantil de cada um levando o reflexo para escola. Então para que isso não aconteça a família deve se conscientizar que ela é o primeiro núcleo de socialização dos indivíduos e o espaço indispensável para a garantia do desenvolvimento e proteção integral de crianças, adolescentes e dos demais membros no meio social.

Pois, a violência no âmbito da família atinge o bem-estar, a integridade física, psicológica, a liberdade, o direito e repercute de forma significativa sobre a saúde das pessoas e sua formação. A violência familiar é uma forma de violência interpessoal que atinge crianças e adolescentes, entranhada na sociedade por meio da cultura que legitima o uso da força como ação educativa.

Para estudar movimento dos processos de interação por meio de reflexões amplia sentidos e significados questionando fundamentos das práticas pedagógicas na formação discentes com relação ao ensino, visando à formação e promovendo uma política de paz 
dentro da escola para que aconteça a patilha e possa trilhar seu próprio percurso de formação. Se a prática de formação tem na sua essência a articulação teoria e prática-práxis.

Tratar de violência na escola significa lidar com uma intersecção de elementos, isto é, um fenômeno de uma nova ordem e não simplesmente o somatório dos objetos, escola e violência. É um fenômeno singular, pois envolve práticas sociais que, para serem compreendidas, requer um olhar que não as reduza a meras extensões de práticas violentas ou escolares. (ABRAMOVAY, 2002, p. 63).

É fundamental a explicitação do seu significado que estabelece no seu programa no estudo sobre o fenômeno ensino e aprendizagem, apresenta para os professores as ações do ato de ensinar os discentes no contexto escolar, toda ação educativa exercida por professores em situações planejada de ensino e aprendizagem, deve considerar as internas as internacionalidade, tendo em vista o que fundamenta a ação docente onde a comunidade escolar reúne crescia diferente mais a formação do cidadão realizada na escola deve favorecer a convivência e paz entre as pessoas.

Portanto, de um enfoque holístico e a importância de ser incorporar o valor da não violência como meta educativa da escola e nova tendência da educação, para a paz centram-se como uma atitude pessoal e coletiva diante da violência em todas as suas manifestações, considerando que a escola deve promover a formação política e social dos alunos como cidadãos e fundamental que ela desenvolva valores éticos baseados da convivência pacifica entre as pessoas, apesar das diferenças, podendo contribuir com uma cultura de paz entre os seres humanos tanto para família como para comunidade.

Dentro da realidade social negativa abundante formas opressivas de vida de relação sociais injusta e que suje as lutas contraria ao mais variados modelos de dominação, desigualdade, descriminação e exploração de si e do próximo, é uma atitude que conduz a assumir o conflito como um fenômeno inerente à interação humana, mas que se tenta resolver de maneira pacifica e respeitosa, num contexto de rápidas mudanças que questionam as muitas formas de existir e de agir das comunidades culturais de cada individuo, é algo mais profundo e por esse motivo.

As novas tendências da educação para a paz diante da violência em todas as suas manifestações sendo necessário que a educação para a paz, aparece transferida a escola atualmente, como um tema transversal, apesar de que a meta educativa demostra o fato de violência estar presente na vida cotidiana e em muitos outros âmbitos fora da escola, de tudo isso deduzimos que a educação para a paz deve mudar a partindo de suas novas diretrizes legais, segue uma perspectiva que privilegia mais a diversidade e a pluralidade de expressões 
de cada educando podendo ser proporcionado pela escola através de educadores treinados adequadamente, promovendo assim a consolidação.

Baseando-se na ideologia que o inspire, e o discente acaba recebendo um conhecimento de si mesmo, e durante o seu percurso na caminhada escolar compreenderá com mais clareza a sua busca do transcendente que contribuirá para a construção da cidadania. É ao longo do percurso do ensino fundamental que se constrói a compreensão sobre as reflexões em que a escola necessita para potencializar cidadãos equilibrados, responsáveis, tolerantes e não-violentos.

É essa capacidade que se deve possuir para a experiência que conduz os processos cognitivos à ação, é a diferença entre a "justiça social" e a "ação política" em um sentido imediato de responsabilidade para acabar com o sofrimento e a opressão deve também partir do sujeito em sua própria iniciativa, levando encontra do que se trata não é só de uma mudança de ação política mas de sua própria decisões diárias de maneira consistente com um alto sentido do proposito e um mais amplo sentido da humanidade e os educadores usarem as suas renovadas habilidades para ensinar os discentes alternativas de não-violência à violência fazendo com que eles busquem formas para construir sua própria existência e serem bem desenvolvidos trazendo a paz para o ambiente escolar, mas para que isso aconteça solicitamos também que os docentes conheçam os fundamentos da sua pedagogia amparados em argumentos que sejam de acordo a necessidade na sintonia escola-vida, colaborando com o progresso da humanidade na busca da justiça e da paz. O desafio sempre é manter os programas sobre a paz e não-violência nas escolas para o controle efetivo da sala de aula desenvolvendo bons projetos que venham ajudar nessa iniciativa de programa de estudos integrados sobre uma paz na escola e não a violência.

Para a integração da família e escola é uma parceria fundamental no desenvolvimento de ações que favoreçam o sucesso escolar e social das crianças na elaboração de projetos escolares para que possam compreender e colaborar com a educação para que favoreça uma aprendizagem significativa, podendo identificar as necessidades, os motivos e a relevância social da proposta realizada selecionando perguntas na situação-problema investigando e pretendendo alcançar a intencionalidade da ação. O ambiente escolar tem sem duvida uma função e se faz necessário que a família procure acompanhar o desempenho da criança no processo de aprendiz tanto na vida familiar quanto na sua atividade desenvolvida dentro da escola.

A relação família-escola é, hoje, tema em destaque na discussão sobre a garantia do sucesso dos alunos na escola. Frequentemente ouve-se dos professores que o apoio 
da família é essencial para o bom desempenho do aluno, porém, muitas vezes essa expectativa de ajuda torna-se fator de acusação, atribuindo-se à família toda a responsabilidade pelo mau desempenho escolar da criança. Quando se tratam de crianças provenientes de classes populares - maioria da população que sofre o chamado fracasso escolar - há de se reconhecer que um modelo de família e de relacionamento entre pais e filhos é tomado como parâmetro. (MARINI E MELLO, 2000, p.1)

Os programas através de projetos escolares que atingem alunos e pais na prevenção a violência buscam além da interrupção promove estimulação intelectual e o sucesso acadêmico futuro o projeto geralmente traz propostas que melhorem a capacidade da criança agressiva tornando-se mais compreensiva e engajados na conscientização da violência de uma convivência tanto escolar quanto a sociedade em geral.

Família e escola promove o desenvolvimento das habilidades dos educandos, a criança se tornará um adulto independente se a família adotar uma educação democrática onde ela possa ser participativa e atuante, pois e a família que ajuda a personalidade na capacidade de enfrentar a realidade do dia-a-dia busca a melhoria educacional da criança na contribuição de uma aprendizagem de qualidade e reconhece que não devemos tratar a violência com motivações sociais com raízes na desigualdade ou na opressão financeira, tratar-se da crueldade plantada na alma e temos que pretender buscar novas questões, gerando reflexões que ultrapassam o regionalismo e tratam de problemas enfrentados pela violência. Segundo (Tiba, 2012 p.247);

Outras pessoas, por falta de limites, por tolerarem menos as frustações do cotidiano, por se acharem no direito de fazer o que têm vontade, sem a mínima consideração com os outros, podem se tornar muito agressivas e impulsivas. Daí para a violência é um passo. A violência é a agressividade natural e adequada que saiu do controle e passou a ser destrutiva.

Se a família e escola estiverem em parceria deve assumir papel de destaque na proteção e participação do professor e funcionários que são muito importante para quebrar o ciclo de impunidade no meio escolar, como por exemplo se o professor suspeita que uma criança ou adolescente está sendo vítima de violência deve conferir, tomando todos os cuidados possíveis fazendo a respeitar sua privacidade e ganhar confiança conversando linguagem simples e clara sobre o combate a violência, esse processo educativo crítico, criativo e significativo na construção do sujeito na interações grupais estimule o espirito investigador por meio de projeto desenvolvido na própria comunidade trazendo um resultado que são utilizado para subsidie a melhoria da qualidade de ação pedagógica como um todo 
ganha escola e buscam além da interrupção da violência, prover estimulação intelectual, aumentar as habilidades cognitiva e o sucesso acadêmico futuro.

\section{METODOLOGIA DA PESQUISA}

Segundo Lakatos (2016, p.139) "A pesquisa, portanto, é um procedimento formal, com método de pensamento reflexivo, que requer um tratamento cientifico e se constitui no caminho para conhecer a realidade ou para descobrir verdades parciais". Nessas poucas palavras podemos descrever a importância do ato de métodos, para o indivíduo no ambiente escolar, com a maioria das vezes podem possibilitar a compreensão do mundo no qual vivemos. Sobre a importância dos métodos para Oliveira (2008, p. 105) "Deve conter a caracterização do material objeto do estudo, a descrição das técnicas ou procedimentos metodológicos utilizados e a forma de tratamento dos dados. Também deve ser definido o tipo de pesquisa a ser realizada (pesquisa bibliográfica, documental, experimental, estudo de caso ou pesquisa-ação, entre outras tipologias possíveis) ".

Segundo Sampieri, Collado e Lucio, (2013, p.550) define "Os métodos de pesquisa mista são a integração sistemática dos métodos quantitativo e qualitativo em um só estudo, cuja finalidade é obter uma "fotografia" mais completa do fenômeno. Eles podem ser unidos de tal forma que a abordagem quantitativa e a qualitativa conservem suas estruturas e procedimentos originais ("forma pura dos métodos mistos").

Segundo Sampieri, Collado e Lucio (p.548, A2013), A meta da pesquisa mista não é substituir a pesquisa quantitativa nem a pesquisa qualitativa, mas utilizar os pontos fortes de ambos os tipos combinando-os e tentando minimizar seus potencias pontos fracos.

Os métodos de pesquisa mista apresentam um procedimento de estrutura de forma original com uma definição adaptada para a realização do estudo de pesquisa na qual contribui para o avanço do conhecimento em todas as ciências, ilustrando maneira mais consistentes com nossa estrutura mental e comportamento habitual, integrando os métodos quantitativos e qualitativos para obter um entendimento profundo.

No desenho empregar-se os métodos mais úteis para a perspectiva teórica por abrange todo processo de pesquisa ou somente a parte de coleta, análise e interpretação sendo um estudo misto envolvendo um trabalho único e próprio em que o pesquisador pode ter uma visão mais completa e holística do problema de estudo, coletando os dados quantitativo e qualitativo em diferentes níveis, sabendo que os analises podem variar em cada um deles, e para localizar e selecionar sua amostra de uma pesquisa mista, o pesquisador de acordo com a 
formulação de seu problema combino, através da investigação técnicas pro balísticas (estatísticas) é técnicas guiadas por num proposito.

Segundo Sampieri, Collado e Lucio (2008, p. 561), o estudo que se desenvolve um desenho especifico para validar os resultados do método com maior propriedade, coletando e analisando os dados em fase do (quem ou qual) nos desenhos sequenciais.

Portanto a pesquisa foi baseada pelo desenho sequencial transformador DITRAS, pois ele integrara duas etapas para análise dos dados, a primeira com sustentação quantitativa em que se fará a abordagem numérica apresentando os percentuais emitidos das opiniões dos sujeitos entrevistados, que sertão interpretados, a segunda fará a constratação entre teoria e prática, evidenciando através do relatório decampo resultados coletados e confrontando com o aporte teórico que sustentou cada variável, além de apresentar um relatório de campo sobre a observação feita no ambiente educacional.

$\mathrm{O}$ enfoque foi definido pelo Misto em que o quantitativo e o qualitativo da pesquisa, prima por evidenciar suas semelhanças e diferenças. Na qual o enfoque qualitativo busca a "dispersão ou expansão" a informação e ter "foco" nas variáveis do estudo. Pois, também se identifica cada característica do enfoque misto e mostrar que todas as duas ferramentas foram igualmente valiosas para o desenvolvimento. Ambos os enfoques empregam processo cuidadosos. De acordo com Sampieri, Collado e Lucio (2013, p. 557), “as etapas nas quais o enfoque quantitativo e o qualitativo costumam ser integrados são fundamentalmente na formulação do problema, no desenho de pesquisa, na amostragem, na coleta dos dados, nos procedimentos de análise dos dados e ou na interpretação dos dados (resultados) ”.

O alcance exploratório possibilita aumentar o conhecimento do pesquisador sobre os fatos, admitindo a formulação mais precisa de problema, são situações nesses estudos que necessitam de planejamento bastante flexível relacionado com o fenômeno que permiti com o analise da pesquisa, "os dados quantitativos e qualitativos são coletados em vários níveis, de maneira simultânea ou em diferentes sequências, às vezes os dois tipos de dados são combinados e transformados para se chegar a novas variáveis e temas para futuros testes ou explorações”. Sampieri, Collado e Lucio (2013, p.565).

Após a abordagem exploratória a pesquisa fez uso do alcance descritivo em que este mostra o cenário, usa dados dos levantamentos, descreve os fatos dos fenômenos de estabelecida realidade caracterizando hipóteses de estudo descritivo relacionado a cultura, limitando uma descrição pura e simples das variáveis buscam especificar as propriedades e as características juntamente com os perfis de pessoas, grupos, objetos, processos, comunidades ou outros fenômeno que se domina a uma observação na qual uma análise planejam medir ou 
coletar informação de forma independente ou um todo sobre os conceitos ou as variáveis que se mencionam. Sampieri, Collado e Lucio (2013). O alcance descritivo é realizado quando o objetivo é examinar um tema ou um problema de pesquisa pouco estudado, sobre a qual temos muitas dúvidas ou que não foi abordada anteriormente os estudos exploratórios servem para se ter mais contato com fenômenos relativamente desconhecidos, obter informação sobre a possibilidade de realizar uma pesquisa mais completa relacionada com um contexto especifico, pesquisar novos problemas, etc.

O instrumento de coletar de dados constituídos e permite que os dados sejam quantificados e submetidos a tratamento estático na preparação do planejamento da entrevista indireta por parte de cada informante que deve responder perguntas relacionadas ao tema, obtendo respostas mais rápidas e exatas. O questionário tem também a finalidade que consiste em traduzir os objetivos da pesquisa, perguntas claras e objetivas com tipos de questões aberta, fechada e múltipla escolha, onde consiste uma participação real do pesquisador com o grupo de pessoas ou a comunidade em geral.

\subsection{ANALISES E DISCURSÕES DOS RESULTADOS}

1- Nas aulas ministradas na escola são abordados o tema violência e indisciplina?

\begin{tabular}{|l|c|c|c|c|c|c|c|c|}
\hline \multirow{2}{*}{ Variáveis } & \multicolumn{2}{|c|}{ Gestão } & \multicolumn{2}{c|}{ Coordenação } & \multicolumn{2}{c|}{ Docente } & \multicolumn{2}{c|}{ Discente } \\
\cline { 2 - 9 } & Fn & F\% & Fn & F\% & Fn & F\% & Fn & F\% \\
\hline $\begin{array}{l}\text { Sim diariamente na } \\
\text { prática docente }\end{array}$ & 01 & $100 \%$ & - & - & 02 & $29 \%$ & 17 & $43 \%$ \\
\hline $\begin{array}{l}\text { As vezes através de } \\
\text { palestras }\end{array}$ & - & - & 01 & $100 \%$ & 03 & $43 \%$ & 05 & $12 \%$ \\
\hline Através de projetos & - & - & - & - & 01 & $14 \%$ & 11 & $28 \%$ \\
\hline $\begin{array}{l}\text { Não tem nenhuma } \\
\text { atividade voltada a } \\
\text { essa temática }\end{array}$ & - & - & - & - & 01 & $14 \%$ & 07 & $17 \%$ \\
\hline Total & 01 & $100 \%$ & 01 & $100 \%$ & 07 & $100 \%$ & 39 & $100 \%$ \\
\hline
\end{tabular}

Interpretação: Conforme se observa na tabela $n^{\circ} 01$, que traz informações referente a se nas aulas ministradas na escola são abordados o tema violência e indisciplina, observa-se que na categoria gestão $100 \%$ dos entrevistados responderam sim diariamente na prática docente. Já na categoria da coordenação $100 \%$ responderam as vezes através de palestras. E na categoria professores $43 \%$ responderam sim diariamente na prática docente, $28 \%$ responderam através de projetos, $17 \%$ responderam não tem nenhuma atividade voltada a essa temática e $12 \%$ responderam as vezes através de palestras

2- Como os alunos reagem diante do tema violência e indisciplina?

Variáveis

\begin{tabular}{l|c|}
\multicolumn{2}{c}{ Gestão } \\
Fn & F\%
\end{tabular}

\begin{tabular}{|c|c|}
\hline \multicolumn{2}{|c|}{ Coordenação } \\
\hline Fn & F\%
\end{tabular}

\begin{tabular}{|l|c|c|c|}
\multicolumn{2}{c|}{ Docente } & \multicolumn{2}{c|}{ Discente } \\
\hline Fn & F\% & Fn & F\% \\
\hline
\end{tabular}




\begin{tabular}{|l|c|c|c|c|c|c|c|c|}
\hline Entusiasmados & - & - & - & - & 02 & $29 \%$ & 08 & $20 \%$ \\
\hline Satisfeitos & - & - & - & - & 04 & $57 \%$ & 18 & $46 \%$ \\
\hline Desinteressados & 01 & $100 \%$ & 01 & $100 \%$ & 01 & $14 \%$ & 06 & $15 \%$ \\
\hline Desmotivados & - & - & - & - & - & - & 07 & $19 \%$ \\
\hline Total & 01 & $100 \%$ & 01 & $100 \%$ & 07 & $100 \%$ & 39 & $100 \%$ \\
\hline
\end{tabular}

Interpretação: Conforme se observa na tabela $\mathrm{n}^{\circ} 02$, que traz informações referente a pergunta como os alunos reagem diante do tema violência e indisciplina, observa-se que na categoria gestão $100 \%$ dos entrevistados responderam desinteressados. Já na categoria da coordenação $100 \%$ responderam desinteressados. E na categoria docente $57 \%$ responderam satisfeitos, $29 \%$ responderam entusiasmados e $14 \%$ responderam desinteressados. E na categoria discente $46 \%$ responderam satisfeitos, $20 \%$ responderam entusiasmados, $19 \%$ responderam desmotivados e $15 \%$ responderam desinteressado

3- Você considera sua escola um espaço violento e preconceituoso

\begin{tabular}{|l|c|c|c|c|c|c|c|c|}
\hline \multirow{2}{*}{ Variáveis } & \multicolumn{2}{|c|}{ Coordenação } & \multicolumn{2}{c|}{ Gestão } & \multicolumn{2}{c|}{ Docente } & \multicolumn{2}{c|}{ Discente } \\
\cline { 2 - 9 } & Fn & F\% & Fn & F\% & Fn & F\% & Fn & F\% \\
\hline $\begin{array}{l}\text { sim muito violento } \\
\text { e preconceituoso }\end{array}$ & - & - & - & - & - & - & 12 & $31 \%$ \\
\hline $\begin{array}{l}\text { pouco violento e } \\
\text { pouco } \\
\text { preconceituoso }\end{array}$ & 01 & $100 \%$ & 01 & $100 \%$ & 03 & $43 \%$ & 06 & $15 \%$ \\
\hline $\begin{array}{l}\text { Não há violência e } \\
\text { nem preconceito } \\
\text { na escola }\end{array}$ & - & - & - & - & - & - & 15 & $39 \%$ \\
\hline $\begin{array}{l}\text { raramente há } \\
\text { violência e } \\
\text { preconceito na } \\
\text { escola }\end{array}$ & - & - & - & - & 04 & $57 \%$ & 06 & $15 \%$ \\
\hline Total & 01 & $100 \%$ & 01 & $100 \%$ & 07 & $100 \%$ & 39 & $100 \%$ \\
\hline
\end{tabular}

Interpretação: Conforme se observa na tabela $n^{\circ} 03$, que traz informações referente a se Você considera sua escola um espaço violento e preconceituoso, observa-se que na categoria gestão $100 \%$ dos entrevistados responderam pouco violento e pouco preconceituoso. Já na categoria da coordenação $100 \%$ responderam pouco violento e pouco preconceituoso. E na categoria docente $57 \%$ responderam raramente há violência e preconceito na escola e $43 \%$ responderam pouco violento e pouco preconceituoso. E na categoria discente 39\% responderam não há violência e nem preconceito na escola, $31 \%$ responderam sim muito violento e preconceituoso, $15 \%$ responderam pouco violento e pouco preconceituoso e $15 \%$ responderam raramente há violência e preconceito na escola.

4- Você considera a comunidade onde o aluno mora um espaço violento e preconceituoso

\begin{tabular}{|c|c|c|c|c|c|c|c|c|}
\hline \multirow{2}{*}{ Variáveis } & \multicolumn{2}{|c|}{ Gestão } & \multicolumn{2}{c|}{ Coordenação } & \multicolumn{2}{c|}{ Docente } & \multicolumn{2}{c|}{ Discente } \\
\cline { 2 - 9 } & Fn & F\% & Fn & F\% & Fn & F\% & Fn & F\% \\
\hline sim muito violento e & - & - & - & - & 02 & $29 \%$ & 05 & $13 \%$ \\
\hline
\end{tabular}




\begin{tabular}{|l|c|c|c|c|c|c|c|c|}
\hline preconceituoso & & & & & & & & \\
\hline $\begin{array}{l}\text { pouco violento e } \\
\text { pouco } \\
\text { preconceituoso }\end{array}$ & - & - & - & - & - & - & 11 & $28 \%$ \\
\hline $\begin{array}{l}\text { Não há violência e } \\
\text { nem preconceito na } \\
\text { comunidade }\end{array}$ & - & - & - & - & - & - & 15 & $38 \%$ \\
\hline $\begin{array}{l}\text { raramente há } \\
\text { violência e } \\
\text { preconceito na } \\
\text { comunidade }\end{array}$ & 01 & $100 \%$ & 01 & $100 \%$ & 05 & $71 \%$ & 08 & $21 \%$ \\
\hline Total & 01 & $100 \%$ & 01 & $100 \%$ & 07 & $100 \%$ & 39 & $100 \%$ \\
\hline
\end{tabular}

Interpretação: Conforme se observa na tabela $n^{\circ}$ 04, que traz informações referente a se você considera a comunidade onde o aluno mora um espaço violento e preconceituoso, observa-se que na categoria gestão $100 \%$ dos entrevistados responderam raramente há violência e preconceito na comunidade. Já na categoria da coordenação $100 \%$ responderam raramente há violência e preconceito na comunidade. E na categoria docente $71 \%$ responderam raramente há violência e preconceito na comunidade e $29 \%$ responderam sim muito violento e preconceituoso. E na categoria discente 38\% responderam não há violência e nem preconceito na comunidade, $28 \%$ responderam pouco violento e pouco preconceituoso, $21 \%$ responderam raramente há violência e preconceito na comunidade e $13 \%$ responderam sim muito violento e preconceituoso.

5- Os alunos são indisciplinados em sala de aula?

\begin{tabular}{|l|c|c|c|c|c|c|c|c|}
\hline \multirow{2}{*}{ Variáveis } & \multicolumn{2}{|c|}{ Gestão } & \multicolumn{2}{c|}{ Coordenação } & \multicolumn{2}{c|}{ Docente } & \multicolumn{2}{c|}{ Discente } \\
\cline { 2 - 10 } & Fn & F\% & Fn & F\% & Fn & F\% & Fn & F\% \\
\hline Sempre & 01 & $100 \%$ & - & - & - & - & 06 & $15 \%$ \\
\hline As vezes & - & - & 01 & $100 \%$ & 05 & $71 \%$ & 23 & $59 \%$ \\
\hline Raramente & - & - & - & - & 02 & $29 \%$ & 02 & $05 \%$ \\
\hline Nunca & - & - & - & - & - & - & 08 & $21 \%$ \\
\hline Total & 01 & $100 \%$ & 01 & $100 \%$ & 07 & $100 \%$ & 39 & $100 \%$ \\
\hline
\end{tabular}

Interpretação: Conforme se observa na tabela $\mathrm{n}^{\circ} 05$, que traz informações referente a se os alunos são indisciplinados em sala de aula, observa-se que na categoria gestão $100 \%$ dos entrevistados responderam sempre. Já na categoria da coordenação $100 \%$ responderam as vezes. E na categoria docente $71 \%$ responderam as vezes e $29 \%$ responderam raramente. E na categoria discente $59 \%$ responderam as vezes, $21 \%$ responderam nunca, $15 \%$ responderam sempre e pobres e $05 \%$ responderam raramente.

6- Em sua escola há ações de combate aos vários tipos de violência?

\begin{tabular}{|l|c|c|c|c|c|c|c|c|}
\hline \multirow{2}{*}{ Variáveis } & \multicolumn{2}{|c|}{ Gestão } & \multicolumn{2}{c|}{ Coordenação } & \multicolumn{2}{c|}{ Docente } & \multicolumn{2}{c|}{ Discente } \\
\cline { 2 - 9 } & Fn & F\% & Fn & F\% & Fn & F\% & Fn & F\% \\
\hline $\begin{array}{l}\text { Sim projetos com a } \\
\text { comunidade }\end{array}$ & - & - & - & - & - & - & 16 & $41 \%$ \\
\hline
\end{tabular}




\begin{tabular}{|l|c|c|c|c|c|c|c|c|}
\hline $\begin{array}{l}\text { Não a escola não } \\
\text { trabalha esse tema }\end{array}$ & - & - & - & - & - & - & 05 & $13 \%$ \\
\hline $\begin{array}{l}\text { Algumas vezes tem } \\
\text { palestras }\end{array}$ & 01 & $100 \%$ & 01 & $100 \%$ & 07 & $100 \%$ & 10 & $25 \%$ \\
\hline $\begin{array}{l}\text { na escola passa } \\
\text { vídeos, tem oficinas } \\
\text { para ensinar a } \\
\text { combater a } \\
\text { violência. }\end{array}$ & - & - & - & - & - & - & 08 & $21 \%$ \\
\hline Total & 01 & $100 \%$ & 01 & $100 \%$ & 07 & $100 \%$ & 39 & $100 \%$ \\
\hline
\end{tabular}

Interpretação: Conforme se observa na tabela $n^{\circ} 06$, que traz informações referente a Em sua escola há ações de combate aos vários tipos de violência, observa-se que na categoria gestão $100 \%$ dos entrevistados responderam algumas vezes tem palestras. Já na categoria da coordenação $100 \%$ responderam algumas vezes tem palestras. E na categoria docente $100 \%$ responderam algumas vezes tem palestras. E na categoria discente $41 \%$ responderam sim projetos com a comunidade, 25\% responderam algumas vezes tem palestras, $21 \%$ responderam na escola passa vídeos, tem oficinas para ensinar a combater a violência e 13\% responderam não a escola não trabalha esse tema.

7-Você já sofreu algum tipo de violência no ambiente escolar?

\begin{tabular}{|l|c|c|c|c|c|c|c|c|}
\hline \multirow{2}{*}{ Variáveis } & \multicolumn{2}{|c|}{ Gestão } & \multicolumn{2}{c|}{ Coordenação } & \multicolumn{2}{c|}{ Docente } & \multicolumn{2}{c|}{ Discente } \\
\cline { 2 - 10 } & Fn & F\% & Fn & F\% & Fn & F\% & Fn & F\% \\
\hline sim verbalmente & - & - & - & - & 03 & $43 \%$ & 02 & $05 \%$ \\
\hline sim fisicamente & - & - & - & - & & & 02 & $05 \%$ \\
\hline $\begin{array}{l}\text { não nunca sofri } \\
\text { nenhum tipo de } \\
\text { violência }\end{array}$ & 01 & $100 \%$ & 01 & $100 \%$ & 04 & $57 \%$ & 12 & $31 \%$ \\
\hline $\begin{array}{l}\text { já com apelidos e } \\
\text { xingamento }\end{array}$ & - & - & - & - & - & - & 23 & $59 \%$ \\
\hline Total & 01 & $100 \%$ & 01 & $100 \%$ & 07 & $100 \%$ & 39 & $100 \%$ \\
\hline
\end{tabular}

Interpretação: Conforme se observa na tabela $\mathrm{n}^{\circ}$ 07, que traz informações referente a pergunta você já sofreu algum tipo de violência no ambiente escolar, observa-se que na categoria gestão $100 \%$ dos entrevistados responderam não nunca sofri nenhum tipo de violência. Já na categoria da coordenação $100 \%$ responderam não nunca sofri nenhum tipo de violência. E na categoria docente $57 \%$ responderam não nunca sofri nenhum tipo de violência e $43 \%$ responderam sim verbalmente. E na categoria discente 59\% responderam já com apelidos e xingamento, $31 \%$ responderam não nunca sofri nenhum tipo de violência, 05\% responderam sim fisicamente e $05 \%$ responderam sim fisicamente.

08- há projetos na escola que trabalhe a violência com os alunos

\begin{tabular}{|l|c|c|c|c|c|c|c|c|}
\hline \multirow{2}{*}{ Variáveis } & \multicolumn{2}{|c|}{ Gestão } & \multicolumn{2}{c|}{ Coordenação } & \multicolumn{2}{c|}{ Docente } & \multicolumn{2}{c|}{ Discente } \\
\cline { 2 - 10 } & Fn & F\% & Fn & F\% & Fn & F\% & Fn & F\% \\
\hline Diariamente & - & - & - & - & - & - & 17 & $44 \%$ \\
\hline Semanalmente & - & - & - & - & - & - & 05 & $13 \%$ \\
\hline
\end{tabular}




\begin{tabular}{|l|c|c|c|c|c|c|c|c|}
\hline Mensalmente & - & - & - & - & 01 & $14 \%$ & 05 & $13 \%$ \\
\hline não há projetos & 01 & $100 \%$ & 01 & $100 \%$ & 06 & $86 \%$ & 12 & $30 \%$ \\
\hline Total & 01 & $100 \%$ & 01 & $100 \%$ & 07 & $100 \%$ & 39 & $100 \%$ \\
\hline
\end{tabular}

Interpretação: Conforme se observa na tabela $n^{\circ} 08$, que traz informações referente a se há projetos na escola que trabalhe a violência com os alunos, observa-se que na categoria gestão $100 \%$ dos entrevistados responderam não há projetos. Já na categoria da coordenação $100 \%$ responderam não há projetos. E na categoria docente $86 \%$ responderam não há projetos e $14 \%$ responderam mensalmente. E na categoria discente $44 \%$ responderam diariamente, $30 \%$ responderam não há projetos, $13 \%$ responderam semanalmente e $13 \%$ responderam mensalmente.

9- O professor preocupa-se me suas alunas em dialogar com seus alunos sobre a violência

\begin{tabular}{|l|c|c|c|c|c|c|c|c|}
\hline \multirow{2}{*}{ Variáveis } & \multicolumn{2}{|c|}{ Gestão } & \multicolumn{2}{c|}{ Coordenação } & \multicolumn{2}{c|}{ Docente } & \multicolumn{2}{c|}{ Discente } \\
\cline { 2 - 10 } & Fn & F\% & Fn & F\% & Fn & F\% & Fn & F\% \\
\hline Sempre & 01 & $100 \%$ & - & - & 02 & $29 \%$ & 10 & $25 \%$ \\
\hline as vezes & - & - & - & - & 05 & $71 \%$ & 17 & $45 \%$ \\
\hline Raramente & - & - & 01 & $100 \%$ & - & - & 02 & $05 \%$ \\
\hline Nunca & - & - & - & - & - & - & 10 & $25 \%$ \\
\hline Total & 01 & $100 \%$ & 01 & $100 \%$ & 07 & $100 \%$ & 39 & $100 \%$ \\
\hline
\end{tabular}

Interpretação: Conforme se observa na tabela $n^{\circ} 09$, que traz informações referente a se o professor se preocupa em suas alunas em dialogar com seus alunos sobre a violência, observa-se que na categoria gestão $100 \%$ dos entrevistados responderam sempre. Já na categoria da coordenação $100 \%$ responderam raramente. E na categoria docente $71 \%$ responderam as vezes e $29 \%$ responderam sempre. E na categoria discente $45 \%$ responderam as vezes, $25 \%$ responderam sempre, $25 \%$ responderam nunca e $05 \%$ responderam raramente.

\section{ANALISE CONCLISIVA}

Observa-se que referente nas aulas ministradas na escola são abordados o tema violência e indisciplina, observa-se que na categoria gestão $100 \%$ dos entrevistados responderam sim diariamente na prática docente. Já na categoria da coordenação $100 \%$ responderam as vezes através de palestras. E na categoria professores $43 \%$ responderam sim diariamente na prática docente, $28 \%$ responderam através de projetos, $17 \%$ responderam não tem nenhuma atividade voltada a essa temática e $12 \%$ responderam as vezes através de palestras.

Sobre a informações referente a pergunta como os alunos reagem diante do tema violência e indisciplina, observa-se que na categoria gestão $100 \%$ dos entrevistados responderam desinteressados. Já na categoria da coordenação 100\% responderam 
desinteressados. E na categoria docente $57 \%$ responderam satisfeitos, $29 \%$ responderam entusiasmados e $14 \%$ responderam desinteressados. E na categoria discente $46 \%$ responderam satisfeitos, $20 \%$ responderam entusiasmados, $19 \%$ responderam desmotivados e $15 \%$ responderam desinteressados.

A informações referente a se você considera sua escola um espaço violento e preconceituoso, observa-se que na categoria gestão $100 \%$ dos entrevistados responderam pouco violento e pouco preconceituoso. Já na categoria da coordenação $100 \%$ responderam pouco violento e pouco preconceituoso. E na categoria docente $57 \%$ responderam raramente há violência e preconceito na escola e $43 \%$ responderam pouco violento e pouco preconceituoso. E na categoria discente 39\% responderam não há violência e nem preconceito na escola, $31 \%$ responderam sim muito violento e preconceituoso, $15 \%$ responderam pouco violento e pouco preconceituoso e $15 \%$ responderam raramente há violência e preconceito na escola.

\begin{abstract}
Violência na escola é aquela que se produz dentro do espaço escolar, sem estar ligada à natureza e as atividades da instituição escolar: quando um bando entra na escola para acertar contas das disputas que são as do bairro, a escola é apenas o lugar de uma violência que teria podido acontecer em qualquer outro local. Violência da escola está ligada à natureza e às atividades da instituição escolar: quando os alunos provocam incêndios, batem nos professores ou os insultam, eles se entregam a violência que visam diretamente à instituição e aqueles que a representam. Essa violência contra a escola deve ser analisada com a violência da escola: uma violência institucional, simbólica, que os próprios jovens suportam através da maneira como a instituição e seus agentes os tratam (modos de composição das classes, de atribuição de notas, de orientação, palavras desdenhosas dos adultos, atos considerados pelos alunos como injustos ou racistas). (CHARLOT, 2002, p. 434).
\end{abstract}

Referente se você considera a comunidade onde o aluno mora um espaço violento e preconceituoso, observa-se que na categoria gestão $100 \%$ dos entrevistados responderam raramente há violência e preconceito na comunidade. Já na categoria da coordenação $100 \%$ responderam raramente há violência e preconceito na comunidade. E na categoria docente $71 \%$ responderam raramente há violência e preconceito na comunidade e $29 \%$ responderam sim muito violento e preconceituoso. E na categoria discente $38 \%$ responderam não há violência e nem preconceito na comunidade, $28 \%$ responderam pouco violento e pouco preconceituoso, $21 \%$ responderam raramente há violência e preconceito na comunidade e $13 \%$ responderam sim muito violento e preconceituoso.

A informações referente a se os alunos são indisciplinados em sala de aula, observa-se que na categoria gestão $100 \%$ dos entrevistados responderam sempre. Já na categoria da coordenação $100 \%$ responderam as vezes. E na categoria docente $71 \%$ responderam as vezes 
e $29 \%$ responderam raramente. E na categoria discente $59 \%$ responderam as vezes, $21 \%$ responderam nunca, $15 \%$ responderam sempre e pobres e $05 \%$ responderam raramente.

Neste sentido referente a pergunta a violência sofrida por alguns alunos atrapalha o seu desenvolvimento enquanto pessoa, observa-se que na categoria gestão $100 \%$ dos entrevistados responderam sim pois estes ficam abalados psicologicamente. Já na categoria da coordenação $100 \%$ responderam sim pois estes ficam abalados psicologicamente. E na categoria docente $57 \%$ responderam sim pois estes ficam abalados psicologicamente, $29 \%$ responderam as vezes atrapalha o desenvolvimento do aluno porque ele passa a não ir para escola e $14 \%$ responderam não, não interfere na aprendizagem. E na categoria discente $39 \%$ responderam as vezes atrapalha o desenvolvimento do aluno porque ele passa a não ir para escola, 26\% responderam sim pois estes ficam abalados psicologicamente, $26 \%$ responderam o aluno não consegue aprender por ter medo de ir para a escola e 11\% responderam não, não interfere na aprendizagem.

\footnotetext{
Abramovay (2003, p.98) afirma ser violência "Magoar, agredir por falta de respeito" que para os jovens são atos de violência por parte dos professores. A desvalorização do profissional professor, a insatisfação, a indiferença e o absentismo dos alunos
}

A informações referente a em sua escola há ações de combate aos vários tipos de violência, observa-se que na categoria gestão $100 \%$ dos entrevistados responderam algumas vezes tem palestras. Já na categoria da coordenação 100\% responderam algumas vezes tem palestras. E na categoria docente $100 \%$ responderam algumas vezes tem palestras. E na categoria discente $41 \%$ responderam sim projetos com a comunidade, $25 \%$ responderam algumas vezes tem palestras, $21 \%$ responderam na escola passa vídeos, tem oficinas para ensinar a combater a violência e $13 \%$ responderam não a escola não trabalha esse tema.

Sobre a pergunta você já sofreu algum tipo de violência no ambiente escolar, observa-se que na categoria gestão $100 \%$ dos entrevistados responderam não nunca sofri nenhum tipo de violência. Já na categoria da coordenação $100 \%$ responderam não nunca sofri nenhum tipo de violência. E na categoria docente $57 \%$ responderam não nunca sofri nenhum tipo de violência e $43 \%$ responderam sim verbalmente. E na categoria discente $59 \%$ responderam já com apelidos e xingamento, $31 \%$ responderam não nunca sofri nenhum tipo de violência, $05 \%$ responderam sim fisicamente e $05 \%$ responderam sim fisicamente.

Conforme pontuam Oliveira e Martins (2007; p.95)

A violência que se configura dentro do espaço escolar, manifestada através do comportamento dos alunos, lança professores diante da confusão da possibilidade de um ensino libertador (caso seja esta a sua proposta) e de uma realidade insuportável, na qual os educadores recorrem a expedientes autoritários e até mesmo 
violentadores, a fim de manter a "ordem geral". São estabelecidas regras, controles, punições e dominações para disciplinar os alunos em estados de rebeldia.

No dia a dia da escola, são recorrentes as reclamações de professores sobre alunos indisciplinados, desinteressados e desmotivados que se recusam a permanecer em sala de aula e a participar das atividades propostas.

Referente a se o professor se preocupa em suas alunas em dialogar com seus alunos sobre a violência, observa-se que na categoria gestão $100 \%$ dos entrevistados responderam sempre. Já na categoria da coordenação $100 \%$ responderam raramente. E na categoria docente $71 \%$ responderam as vezes e $29 \%$ responderam sempre. E na categoria discente $45 \%$ responderam as vezes, $25 \%$ responderam sempre, $25 \%$ responderam nunca e $05 \%$ responderam raramente.

\section{REFERÊNCIAS}

ABRAMOVAY, Mirian; RUA, Maria das Graças. Violências nas escolas. Brasília: UNESCO, Instituto Ayrton Senna, Unaids, Banco Mundial, Usaid, Fundação Ford, Consed, Undime, 2002.

ABRAMOVAY, Mirian. Gangues, galeras, chegados e rappers: juventude América Latina: desafios para políticas públicas. Brasília: UNESCO. BID, 2002.

ABRAMOVAY, Mirian et al. Escola e violência. Brasilia: UNESCO, UCB, 2003.

CANDAU, Vera. Oficinas Pedagógicas de Direitos Humanos-Vozes-RJ-1995.

CHARLOT, Bernard. ÈMIN, Jellab, A. (coords) Violences à l'école: état des savoirs. Paris: Mason 7 Armand colin, 1997.

A violência na escola: como os sociólogos franceses abordam essa questão. Sociologias, Porto Alegre, v. ano 4, n. jul-dez, p. 432-442, 2002.

HERNÁNDES Sampieri, Roberto. Metodologia de pesquisa. /Carlos Fernández Collado.; María del Pilar Baptista Lucio; tradução: Daisy Vaz de Moraes; revisão técnica: Ana Gracinda Queluz Garcia, Dirceu da Silva, Marcos Júlio. 5.ed.- Porto Alegre: Penso, 2013.

LAKATOS, Eva Maria.; MARCONI, Marine de Andrade. Fundamentos de metodologia científica. 7. ed.- São Paulo: Atlas. 2016.

MARINI F.; MELLO R. R., Relação entre a escola e famílias de classes populares: Desconhecimento e desencontro, Caxambu, ANPED, 2000. 
OLIVEIRA, Valéria Rodrigues de. Desmitificando a pesquisa científica. Belém: EDUFPA, 2008.

Oliveira, W. A. D., Silva, J. L. D., Yoshinaga, A. C. M., \& Silva, M. A. I. (2015). Interfaces entre família e bullying escolar: uma revisão sistemática. Psico - USF.

SILVA, J. M. A. P.; SALLES, L. M. F. A violência na escola: abordagens teóricas e propostas de intervenção. In: Educar em Revista, Curitiba: UFPR, nº. Especial 2, p. 217-232, 2009.

TELLES, Vera-Violência e Cidadania-In Violência no Esporte-vários autores - Secretaria da Justiça e da Defesa da Cidadania-SP-1996

TIBA, Içami. Quem ama educa! Formando cidadãos éticos- São Paulo: Integrare Editora, 2012. 